\title{
DIOS, CRISTO Y EL MALIGNO: DISPUTAS COSMOLÓGICAS Y CICLOS TEMPORALES EN SAN ANTONIO DEL CAJÓN (PROVINCIA DE CATAMARCA, ARgENTINA)
}

\author{
Bárbara Martínez
}

\section{* Introducción}

Resumen

En San Antonio, Catamarca, Argentina, la disputa entre las fuerzas de Dios y Cristo, y el maligno es narrada por la gente del lugar como un principio ordenador del mundo. En ella, las personas toman partido activamente a través de la acción ritual. En este artículo presento y discuto cómo esta pugna se plasma en el ciclo anual y el ciclo diario.

En particular, sugiero que los lazos cosmológicos que se expresan anualmente se reiteran a escala diaria, de modo que la jornada resulta una repetición microcósmica que se instaura bajo similares principios organizativos que el ciclo anual.

Palabras claves: cosmología - tiempo - ritual.

\begin{abstract}
In San Antonio, Catamarca, Argentina, the dispute between God and Christ's forces, and evil's is narrated by the locals as a world's ruling principle. In it, people take active participation through the ritual action. In this article I present and discuss how this conflict is shaped in the yearly and daily cycles. In particular, I suggest the cosmological liaisons that are expressed annually, are repeated on a daily basis, in a way that the day results in a microcosmic repetition that is presented under similar organizing principles to those of the yearly cycle.
\end{abstract}

Key words: cosmology - time - ritual.

Recibido: mayo 2014. Aceptado: octubre 2014.

\footnotetext{
1 Facultad de Filosofía y Letras, Universidad de Buenos Aires. CONICET. Sarmiento 3969 14 A, Buenos Aires, ARGENTINA. Email: bmartinez@ filo.uba.ar.

2 Bajo la denominación maligno o malo resuenan los ecos de la figura que el discurso cristiano ha llamado demonio. Volveré sobre este punto.
}

En la localidad de San Antonio, ubicada el valle de El Cajón, en la provincia de Catamarca, Argentina, el calendario anual de actividades posee momentos que son ritualizados. Algunas de sus etapas, como estudiaré, se encuentran relacionadas con eventos que ilustran una pugna cosmológica entre Dios, Cristo y el maligno, ${ }^{2}$ en la que los hombres participan activamente, y cuyas derivaciones se verifican en el ciclo diario. En las últimas décadas, la literatura especializada en el área geográfica andina ha producido amplia evidencia acerca del modo en que el tiempo es socialmente construido, realizando fructíferos esfuerzos por analizar críticamente los modos en que se organizan los ciclos temporales. Para algunos, los conceptos sobre el tiempo que se formulan en las festividades contemporáneas son de larga data y expresan el paso del pasado al presente (Randall 1982). Otros autores, articulando el discurso religioso con la música, han sugerido que el calendario de fiestas es un programa mediante el cual los hombres manipulan a las entidades en su favor, bajo la apariencia de una sistema donde éstas figuran como las beneficiarias de los dones que los hombres les otorgan (Martínez 2001). Asimismo, fructíferas contribuciones han vinculado los procesos de configuración de las identidades locales con la prevalencia de diversas entidades en específicos momentos del ciclo productivo (Rivière 1991; Fernández Juárez 2006). También han sido estudiadas las representaciones de tiempoespacio en relación a los procesos de resignificación de las festividades religiosas (Gavilán y Carrasco 2009). 
En el noroeste argentino, el ciclo anual ha generado numerosos y variados estudios desde la antropología social. Desde una perspectiva teórica caracterizada por el sincretismo, Ana María Mariscotti (1966) sugirió la existencia de un extenso período de primavera similar a un carnaval prolongado, "relicto" de antiguas celebraciones de apertura y cierre del ciclo agrícola. A este trabajo se suma la indagación de Ciro René Lafón (1970), quien propuso la existencia de una discrepancia entre el calendario europeo y el "aborigen". En el marco de un enfoque que considera las expresiones religiosas como un mecanismo adaptativo, Rodolfo Merlino y Mario Rabey (1978 y 1983) postularon la presencia de un ciclo ritual-religioso fruto de la coexistencia, en paralelo, de creencias "nativas" y "cristianas". Focalizando en el modo en que las personas creativamente se apropian del pasado, generando nuevos significados en ese proceso, trabajos recientes interpretaron algunos eventos del calendario ritual vinculando música e identidad colectiva (Avenburg 2012) y ritual y memoria (Martínez 2013a). Los aportes sobre el ciclo diario, sin embargo, son escasos. Los momentos socialmente relevantes de la jornada suelen ser mencionados en el marco de indagaciones más amplias, dedicadas, por ejemplo, a tesoros enterrados (Sturzenegger 1981), al ordenamiento del espacio (Rubinelli 2000) o a los rituales de carnaval (Costa y Karasik 1996).

En esta indagación realizo una aproximación analítica al ciclo anual y al ciclo diario en San Antonio. Allí, los eventos que se desarrollan durante el año se vinculan con los órdenes cosmológico, ontológico y ecológico, pero también con las especificidades de la relación entre esa población y las vecinas. Entonces, en particular, estudio las discontinuidades temporales, es decir, las distinciones en el tiempo relevantes en lo referido a la acción ritual, que constituyen los ciclos anual y diario, sugiriendo que este último, en varios sentidos, aparece como una repetición microcósmica, bajo similares principios organizativos, que el ciclo anual. Me interesa precisar que diversos lazos cosmológicos que se expresan a escala anual, también lo hacen durante la jornada cotidiana.

Mi análisis se suma al interés clásico de la antropología por analizar las articulaciones entre tiempo y sociedad. Ya en 1912 los trabajos de Durkheim exploraron el modo en que el tiempo es clasificado y representado a partir de categorías sociales (Durkheim 2007 [1912]). Estudios posteriores han mostrado que los repertorios temporales sirven no sólo para medir su transcurso, sino también para demarcar las modalidades con que éste se manifiesta en la experiencia (Geertz 1997 [1973]). Ésta, sin embargo, no es unívoca, de modo que diferentes distinciones temporales pueden articularse en una misma sociedad, tomando distinta preponderancia de acuerdo a contingencias específicas (Bloch 1977). Pierre Bourdieu (2007) ayuda a pensar estos tópicos cuando sugiere que los períodos de transición se asemejan a umbrales que promueven el encuentro de elementos antagónicos, en los que se producen pugnas simbólicas. El autor señala que durante su transcurso, la acción ritual apunta a maximizar los beneficios requeridos de las entidades tutelares: en particular, "asegurar la concordancia entre la cronología mítica y la cronología climática" de modo que la lluvia coincida con el momento de la siembra, que el paso de la estación seca a la húmeda, y viceversa, siga un recorrido sin entorpecimientos, obteniendo raudamente el provecho del ciclo que comienza, y reteniendo lo máximo posible los beneficios del anterior (Bourdieu 2007: 358). Ello resulta central en sociedades donde el entorno no constituye un elemento neutral, sino que se halla concebido a partir de relaciones entre sitios, seres que los pueblan, itinerarios y usos sociales (Nates Cruz 2009). Los repertorios temporales, además, constituyen un campo de disputas, un inventario de sentidos donde lo político y lo litúrgico pugnan por significar fechas y entramados simbólicos (Del Campo Tejedor 2006). Me interesan también los aportes que realiza Thomas Abercrombie (2006 [1998]) sobre los procesos de interacción activa y creatividad cultural que las personas instauran en su andar por el mundo.

Como mencioné, mi indagación se centra en San Antonio, donde realicé sucesivos trabajos de campo entre los años 2004 y 2010. Las entrevistas abiertas de sesiones múltiples y la observación participante constituyeron los métodos privilegiados para abordar la temática. Puesto que esa población no fue estudiada sistemáticamente mediante un enfoque vinculado a la antropología sociocultural hasta la investigación realizada por la autora, y con el objeto de profundizar en especificidades de la sociedad local, en este texto prevalece la presentación de la información etnográfica. 
El trabajo se organiza en tres secciones. En la primera, examino cómo se conforma la estructura económica y social local, así como algunas de sus articulaciones con Santa María, ciudad capital del Departamento en que se concentra esta pesquisa. En la segunda y tercera, respectivamente, estudio los eventos que caracterizan el ciclo anual y el ciclo diario. Finalmente, sugiero que ambas configuraciones, en términos generales, se hallan influidas por la disputa entre Dios, Cristo y el maligno, respondiendo a similares principios organizativos.

\section{* El lugar}

El valle de El Cajón se ubica al interior del Departamento de Santa María, cuya ciudad central, que lleva el nombre homónimo, es el centro administrativo, político y eclesiástico del área. Desde el punto de vista ecológico, el ambiente se transforma de norte a sur. En líneas generales se trata de un valle semiárido caracterizado por precipitaciones estivales y gran amplitud térmica estacional y diurna (De Hoyos 2004).

El poblado de San Antonio se consolidó hacia fines del siglo XIX como producto de la fragmentación de tierras en manos de algunas pocas familias. Éstas otorgaron en carácter de donación los terrenos para la construcción de los espacios públicos como la capilla, el cementerio, la plaza, la iglesia y la escuela, de acuerdo a los testimonios que he estudiado hasta el momento, así como también por la información proveniente de la documentación consultada, que se encuentra en archivos personales. ${ }^{3}$ Desde el punto de vista socioreligioso, según los relatos recabados, desde inicios el siglo XX la evangelización intensificó su discurso alrededor de Dios y de Cristo, puesto que con anterioridad los santos constituían los destinatarios centrales de la acción ritual.

Una dificultosa accesibilidad geográfica, matizada por la creación de un camino de huella en la década de 1980, caracteriza al poblado. En términos generales, la economía del lugar se basa en la agricultura, la ganadería y el

\footnotetext{
3 Me refiero al archivo personal de Alberto Pacheco, un hombre que habita un puesto a aproximadamente cinco kilómetros del poblado. He estudiado en otro sitio (Martínez 2011) parte de la documentación que él posee.
}

trabajo en el Estado nacional, provincial y municipal. Cada unidad doméstica posee o arrienda entre una y tres hectáreas que cultiva para la subsistencia, mientras que intercambia o vende el excedente con sus vecinos. Los últimos años, los hogares han cumplimentado sus ingresos con el dinero proveniente de Planes de Asistencia y de pensiones no contributivas. El poblado no cuenta con energía eléctrica. La falta de mano de obra masculina, producto de la migración a los polos de cosecha de frutales, como Santa María y Cafayate, acarrea grandes problemas para la continuidad de la sociedad local (Martínez 2013b). La adscripción al catolicismo constituye un fenómeno religioso mayoritario. Las alternativas religiosas no han tenido prácticamente incidencia, pues suelen considerarse una amenaza a su sistema de creencias y a su identidad, fuertemente sustentada en las prácticas católicas.

San Antonio se constituyó como una población subordinada a Santa María en virtud de su carácter de ciudad cabecera de Departamento (ver Figura 1). Su dificultosa accesibilidad geográfica, la disposición de recursos como fuentes de agua, y su rol dependiente de la ciudad capital, contribuyeron a consolidar imaginarios contrapuestos e interconectados mutuamente. ${ }^{4}$ Entre ellos, se lo considera como un sitio "con agua y aire más puro" debido a su cercanía al cerro Chuscha, de cuyo deshielo nace el río Santa María. El imaginario más relevante para los fines de este artículo es el que define a las personas de San Antonio estando "lejos" desde el punto de vista espacial, y también temporal. Muchos santamarianos vinculan a la gente local con un pasado precolombino arquetípico y presocial (pues "se casan entre ellos" y adolecen de "falta de higiene", entre otros tópicos) (Martínez 2011). En este sentido, refiriéndose a las poblaciones del valle de El Cajón, suele decirse que "los indios están en el cerro". Mientras tanto, sus productos (como los vegetales que cultivan y los animales que crían) son altamente valorados. También sus especialistas rituales son muy requeridos. La gente local ha aprendido a sacar provecho de ello. Haciendo uso de un esencialismo estratégico (Spivak 1987) comercializa sus productos y su eficacia ritual en algunos momentos del ciclo anual, como indicaré más adelante.

\footnotetext{
4 Sobre estos imaginarios y las penetraciones de la modernidad en San Antonio, puede consultarse el estudio de Martínez (2013c).
} 


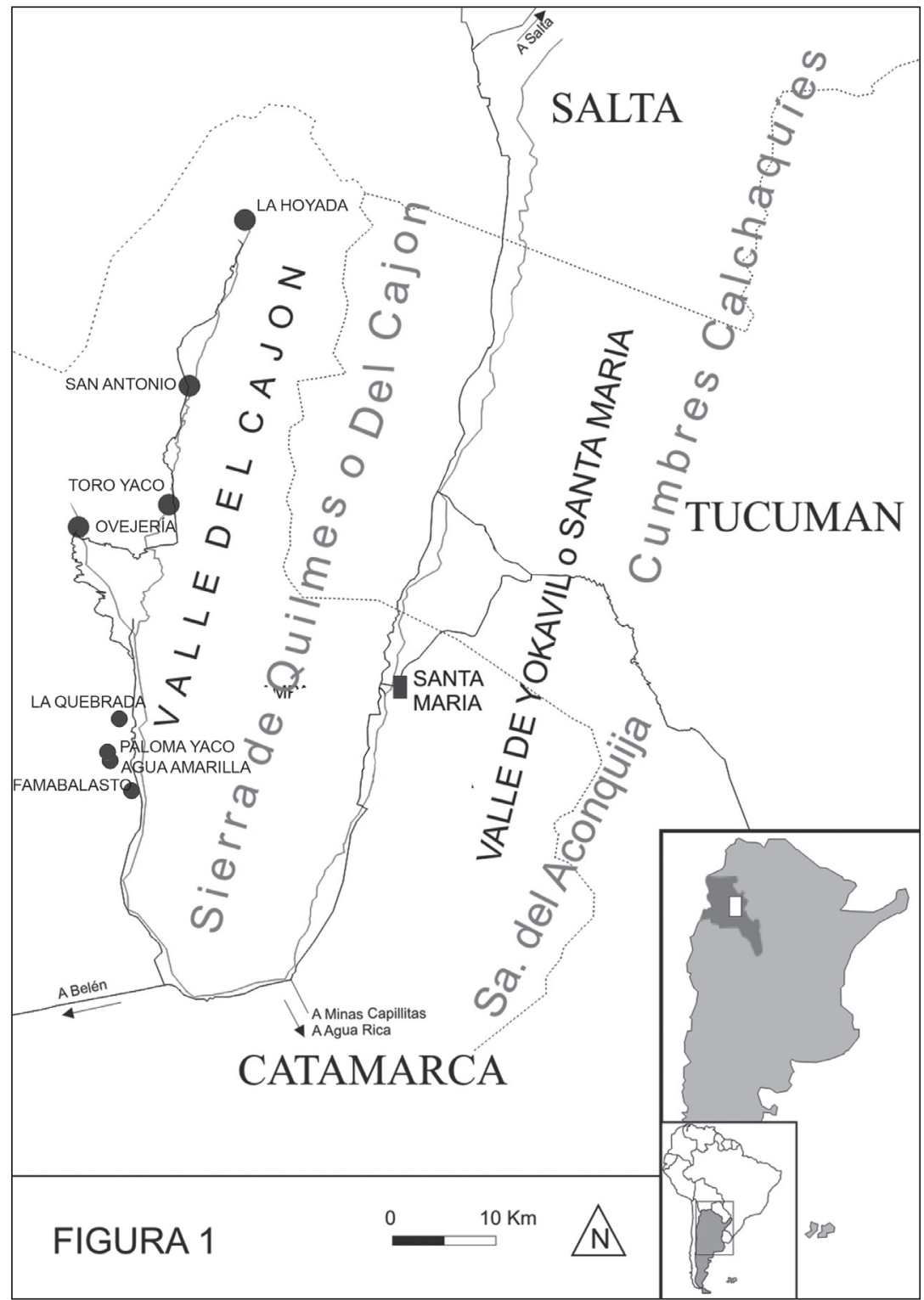

Figura 1. Mapa del área.

* El orden cosmológico y la sucesión DE ESTACIONES

En San Antonio, en términos generales, el poder que en última instancia ordena el mundo, y que repercute en virtualmente todas las actividades de las personas, proviene de Dios. Su supremacía, sin embargo, en ocasiones es disputada por el maligno y sus seres auxiliares. Ello provoca un desbalance de fuerzas que, como mencioné, se expresa con diferente intensidad en algunos momentos del ciclo anual y del ciclo diario.

Para dar cuenta de estas ideas, en primer lugar me adentraré en los niveles cosmológicos que la gente identifica, con el objeto de comprender la organización de ambos ciclos.

La información etnográfica sugiere que el cielo es el lugar donde habitan Dios y Cristo (su Hijo). Como adelanté, la 
atención ritual hacia ambos parece haberse incrementado a partir de inicios del siglo XX, con la labor evangelizadora de los sacerdotes, pues antes "sólo a los santos conocíamos", según mencionara una de las pobladoras. A nivel local, ambos están relacionados especialmente con el lapso de la jornada en el que se halla presente la luz solar. En el cielo también se ubican los santos, que son los intermediarios entre Dios, Cristo y los hombres. Como veremos, a ellos les compete transmitir a Dios los pedidos de la gente y protegerla haciendo uso del poder emanado de Él, que obtienen en la capilla en algunos momentos del ciclo anual. Los muertos se caracterizan por ocupar unas veces un espacio difuso, y otras, cierta ubicuidad. Estos pueden promover la fertilidad y la abundancia, a través de la caída de las lluvias, pero también enfermar a las personas si éstas se topan sorpresivamente con ellos. Por su parte, la tierra es el sitio donde moran las personas, los animales, las plantas y los seres como la Pachamama y los duendes. En el área la Pachamama denota características polisémicas, pues representa en sí misma múltiples manifestaciones. Por ejemplo, puede presentarse en un encuentro eventual con un campesino bajo la imagen de una mujer joven o anciana, con atributos ligados a las tareas agrícola-pastoriles y de hilandería (huso, ushutas ${ }^{5}$ y sombrero de ala ancha, del tipo que utilizan las personas durante el pastoreo). Pero también se manifiesta bajo la forma de los animales que se encuentran bajo su dominio. Las personas afirman que de las vicuñas y los felinos que habitan los cerros, "la Pachamama es la dueña". En términos generales, a ella pertenecen los animales silvestres. Por eso, controla que la caza no sea excesiva. Además, provee los bienes que el suelo brinda, de modo que también se trata de la tierra, en el sentido de substrato material sobre el que se reproducen los hombres, los cultivos y el ganado. ${ }^{6}$ Los duendes son espíritus jocosos de niños muertos sin bautizar, o como producto de un aborto. En la narrativa local, deambulan en "pata pila" (es decir, descalzos) en busca de otros infantes con los que jugar. También se divierten escondiendo objetos que los adultos utilizan durante su trabajo diario. Algunos autores reportan que entre sus

\footnotetext{
5 Me refiero a un tipo de calzado confeccionado a partir de llantas de automóviles, de gran resistencia para el tránsito en la escarpada geografía local.

6 Estos resultados se asemejan a los estudiados por García y Rolandi (2000) en la cercana área de Antofagasta de la Sierra, Catamarca.
}

actividades también está retener a los niños llevándolos consigo (Bianchetti 1984). Por otra parte, de modo diferente a lo que ocurre en el Altiplano Septentrional, en San Antonio a los cerros no se les brinda un conjunto ceremonial distintivo ni se los denomina Apus. Sin embargo, no constituyen sitios inertes (Merlino y Rabey 1983). Muchos de ellos presentan cualidades específicas relacionadas con el modo en que la historia local se inscribe en el paisaje (Martínez 2014). Además, como ocurre en el espacio jujeño, sus poderes son temibles, pues pueden provocar enfermedades a los hombres, como el "mal de aire", cuyos síntomas son dolor de cabeza, mareos y vómitos (Vilca 2009). Finalmente, el maligno o malo es un ser que posee sugerentes conexiones con el diablo cristiano. Capaz de apropiarse enfermedades a los pastores si éstos se duermen en estado de ebriedad en el campo (Bianchetti 1984), también es el responsable de predisponer a una persona a cometer un suicidio, tal como fue mencionado en San Antonio para un caso ocurrido en el año 2007. A la par, puede entregar dones a los hombres, como la facultad para tocar hábilmente instrumentos musicales. En la narrativa local esta entidad se encuentra acompañada de una serie de seres auxiliares de características difusas. Estos conforman un séquito de colaboradores que lo asisten en diversas tareas, tomando partido por él en su pugna contra Dios y Cristo.

En San Antonio, las jornadas están sujetas a coordenadas más amplias derivadas del devenir de las estaciones y de los rituales que se ajustan a los cambios cíclicos. Las personas clasifican el tiempo anual, conciliando el compás del mundo natural con la acción socialmente ritualizada.?

Para encauzar los poderes de Dios, la gente evoca a una cohorte de entidades. Los santos y los muertos ocupan aquí un lugar especial por su carácter de mensajeros e intermediarios entre el plano cosmológico celeste donde se sitúa al dominio de Dios, y la morada de los hombres en la tierra. Los muertos que las personas recuerdan dentro de la memoria genealógica de dos o tres generaciones en línea ascendente son confiables aliados pues conocen y

\footnotetext{
7 Se pueden encontrar interesantes contribuciones sobre la relación entre el calendario ritual y el productivo en la puna jujeña, por un lado, y la concepción indígena de la recreación del mundo contenida en la estética de las imágenes cristianas, por el otro, en Bugallo (2010).
} 
han participado de las vicisitudes que la vida campesina depara. Además también están ligados a los vivientes por relaciones mutuas de parentesco, compadrazgo y amistad.

El comienzo de la estación de lluvias, hacia fines de octubre e inicios de noviembre, enlaza con los ritos de Todos los Santos y el Día de las Almas. Es el momento en que la siembra termina y comienza la cosecha, de modo que se espera la acción de las fuerzas generadoras de los muertos. Las personas creen que las almas ${ }^{8}$ arriban el 1 de noviembre al mediodía, para retirarse nuevamente al día siguiente. Éstas pueden ser devastadoras si no se cumple con las obligaciones recíprocas. Por eso las colman -pues han sido hombres- de dones alimenticios y los reciben como visitas privilegiadas.

La tarde del 30 de noviembre de 2008 , don Reino Condorí, un hombre en cuyo hogar y el de su familia me hospedé en numerosas oportunidades, me invitó a carnear una llama en casa de su hija Claudina para homenajear a las almas. Cuando llegué para acompañarlos, los niños jugaban animadamente con el animal mientras los adultos cavaban un pozo en la galería donde desembocan los cuartos que componen la vivienda. Como el corral, la casa y la capilla, orientamos su cabeza hacia el este. ${ }^{9}$ La Pachamama participa en cada sacrificio de ganado. Aque-

\footnotetext{
8 Sobre la taxonomía local de las almas puede consultarse el trabajo de Martínez (2011).

9 El simbolismo relacionado con el este y el oeste constituye una temática relevante en los estudios sobre el área geográfica andina. Al respecto, Tom Zuidema (1981) ha sugerido que el este se vincula con el nacimiento y el crecimiento, mientras que el oeste con el decrecimiento y muerte. En San Antonio existe una amplia serie de proscripciones rituales asociadas con el eje simbólico esteoeste. Por ejemplo, la posición en que la gente coloca el ganado para carnearlo está regida por este eje. También los cortes que se realizan para desmembrarlo siguen ese sentido. Así, para retirar las vísceras se secciona su cuero desde el ángulo más cercano a la persona que está realizando el trabajo, hacia la cabeza del animal, que se encuentra dirigida hacia el este. Es que en términos generales, en diversos rituales este punto cardinal se encuentra relacionado con la propiciación. El oeste, en cambio, se asocia con lo estéril y con el mundo de los muertos. Por ello los rezos ligados con la fertilidad no se realizan hacia el oeste. En su vida diaria, tampoco las personas duermen con su cabeza apuntando en esa dirección, pues es el modo en que yacen los difuntos en sus tumbas (Martínez 2011).
}

lla vez vertimos la sangre en el hoyo y la acompañamos con una ración de coca y algunas libaciones de alcohol en forma de cruz. Aunque aún restaban dos jornadas para la llegada de las almas, doña Teresa Aguaysol, la esposa de don Reino, me había puesto sobre aviso de que carnearíamos aquel día pues el siguiente, 31, era viernes. Es que en el terreno del simbolismo calendárico, martes y viernes son días aciagos. Por eso, existe una compleja serie de prescripciones y proscripciones rituales que condiciona la acción humana durante estas jornadas y muchas actividades, especialmente las vinculadas con la propiciación, son tabú ${ }^{10}$ (volveré sobre este punto). Aquella tarde fuimos muy afortunados. Mientras lavábamos las vísceras del animal, hallamos una dureza de un color levemente dorado que recordaba a una piedra. ${ }^{11}$ La guardaron, explicándome que era un signo inequívoco de "suerte". ${ }^{12}$

Durante este lapso, que transcurre entre los días previos y posteriores al 1 y 2 de noviembre, las fronteras se tornan permeables, allanando la comunicación entre los niveles cosmológicos, lo que promueve la admisión de las demandas humanas. Sin embargo, los hombres deben recordar a sus muertos que ya no forman parte de este mundo y las formas materiales que éste guarda dejaron de pertenecerles con su deceso. Así, en la víspera de la llegada de las almas, señalan ${ }^{13}$ unos pocos animales para enseñarles que ahora ellos son los dueños, pues se cree que de no hacerlo, los difuntos podrían llevarlos consigo, matándolos.

\footnotetext{
${ }^{10}$ Flores Ochoa (1974) ha resaltado la evitación de realizar ceremonias propiciatorias los días martes y viernes para el caso de los pastores de altura en Perú. La investigación de Rubinelli (2000) sobre las concepciones del espacio y el tiempo en la Quebrada de Humahuaca (Jujuy, Argentina), sostiene que ambas jornadas son peligrosas. Para la autora, "parecen ser días en que las fuerzas subterráneas cobran especial influencia sobre la vida" (Rubinelli 2000: 152). En su estudio sobre el calendario ritual en los Departamentos de Chuquisaca y Potosí (Bolivia), Gabriel Martínez (2001) ha sugerido que los martes y viernes son días propios del Saxra (diablo).

${ }^{11}$ La piedra bezoar es una concreción calculosa producida en el aparato digestivo de algunos camélidos.

12 Suerte es un término referido a objetos y eventos que se asocian con una capacidad de agencia no controlada por las personas.

${ }^{13}$ Las señaladas son rituales en los que se sahúma el ganado, se lo decora con flores de lana y se lo salpica con bebidas, procurando promover así el incremento del número de animales que cada persona posee (Ambrosetti 2001 [1917], Martínez 2011).
} 
El inicio del año en el calendario gregoriano está marcado por un encadenamiento de jornadas calurosas y húmedas, que continuarán hasta el mes de marzo, cuando suele desatarse un corto período de heladas nocturnas. Este lapso está atravesado por momentos de gran inestabilidad. Se considera que enero y febrero son meses moderadamente peligrosos, pero el 1, 2 y 3 de enero lo son especialmente, pues en ellos la gente es proclive a sufrir accidentes -particularmente quebraduras- durante sus incursiones a los cerros. ${ }^{14}$ Como volverá a ocurrir el 1 de agosto, el 1 de enero las personas se repliegan a sus casas. Es que el mundo se inquieta. Eso no impide que los hombres saquen provecho de la situación, manipulando la inestabilidad y encauzándola para sus propios fines. De este modo, las personas pueden leer en la "naturaleza"15 fórmulas anticipatorias de los procesos humanos. Así, a través de técnicas adivinatorias como la lectura de la humedad debajo de las piedras, predicen los rasgos climatológicos que marcarán el resto del año. Es un mal presagio que el año comience un lunes, martes o viernes. En el terreno del simbolismo calendárico, el lunes está destinado a los difuntos y, por regla general, como mencioné, los martes y viernes se consideran días nefastos.

${ }^{14}$ Los días 1, 2 y 3 de enero, algunas jornadas de la Semana Santa y el 1 de agosto las personas están más expuestas a quebrarse en sus incursiones a los cerros. Las definiciones locales sobre este punto suelen ser vagas e imprecisas. Pese a ello, puedo suponer que detrás se expresan principios de conceptualización del tiempo más extendidos en el área geográfica andina, que guardan sutiles conexiones con la evidencia etnográfica que puntualizamos. Inicios de agosto es, para algunas comunidades aymaras del norte de Chile, el comienzo de año (Gavilán y Carrasco 2009). En San Antonio, este período marca el tránsito a un momento propiciatorio, luego del cual se inaugura la época de siembra. Es, pues, el inicio del ciclo agrícola anual. Más evidente es la "ruptura" entre un año y otro que marca el inicio de enero, así como el desequilibrio de poderes que caracteriza la Semana Santa, como ilustraré luego. Sugiero que se trata de tiempos liminales donde la transición marca una fase de inestabilidad para los hombres y el mundo que los rodea. En este caso, esa inestabilidad parece manifestarse en cierta fragilidad en la estructura corporal.

${ }^{15}$ En el contexto local, la naturaleza no es una esfera separada de las personas. Existen complejos lazos que articulan a los hombres, los animales, las plantas y los objetos del paisaje (Descola 1998:25), que no pueden ser explicados mediante el dualismo moderno que distribuye humanos y no humanos en marcos ontológicos independientes.
Rituales propiciatorios como las señaladas se inician en diciembre, se intensifican en Navidad, Año Nuevo, 1 de enero, y culminan luego de Semana Santa. Si bien la estación de lluvias comienza en noviembre, éste es el momento con mayor cantidad de precipitaciones, lo que trae como consecuencia el anegamiento del único camino que une el valle con los otros poblados. Esto provoca un virtual aislamiento de la población, con frecuencia por varias semanas.

Cuando el sol abrasador recalienta la superficie de la tierra es cuando más se necesita de los poderes intermediarios de los santos para propiciar la caída -o el cese- de las lluvias. ${ }^{16}$ Las plantas brotan y también lo hacen los retoños animales, pues es la época de las primeras pariciones. Para canalizar las fuerzas de los santos, la gente se congrega en la capilla bajo el fervor de la Misión Anual, que se realiza durante febrero, en una fecha escogida por el sacerdote proveniente de Santa María. Este es el único momento del año en que contarán con la presencia del párroco -salvo una visita fugaz durante los festejos patronales de junio-. Las fuerzas que movilizan los sacerdotes son de naturaleza distinta -aunque complementaria- que las que detentan las personas con "poder" ${ }^{\text {"17 }}$, aunque en ambos casos éstas provienen de Dios, que es su fuente principal. Así, es el momento de los bautismos, comuniones, confirmaciones, bodas y la unción de los enfermos. Las personas entienden que los óleos sagrados que ellos manipulan -y que, según me explicaron, llegan desde los sitios que las Sagradas Escrituras mencionan, como Jerusalén- sintetizan y condensan las fuerzas celestiales. Junto al agua bendita, son altamente valorados en contextos de curación.

${ }^{16}$ Durante el trabajo de campo no he presenciado rituales para detener la lluvia, aunque han sido descritos para otros sitios de los Andes (Gil García 2012).

${ }^{17}$ Darío Humano, el agente sanitario que me albergó junto a su familia durante varios de los trabajos de campo que realicé en San Antonio, me explicó que es Dios quien beneficia a la gente con "poder", junto con Cristo, pues Él fue el primero en curar. También me dijo que las principales herramientas con que cuentan estas personas son las oraciones cristianas, como el Padre Nuestro y el Ave María. Darío me contó que, por regla general la mayoría de ellos adquieren sus habilidades mediante el aprendizaje por imitación, aunque algunas personas me indicaron también que devienen en especialistas rituales los afectados por la caída de un rayo (Fernández Juárez 2000). 
Durante la Misión Anual, Ovejería, San Antonio y Toro Yaco reciben al sacerdote, que permanece nueve días en cada poblado. Envueltos en una red de obligaciones recíprocas, los hombres y los santos intercambian visitas en estas fiestas. Cuando la gente de San Antonio narra su pasado, dice que en un tiempo primigenio los santos vivieron en este mundo, recorriéndolo. Como un modelo originario de lazo social, se visitaban entre sí, tal como lo hace la gente actual. Por ello, en la Misión Anual, las figuras de bulto de los patronos de las localidades vecinas y los santos de los altares familiares ${ }^{18}$ son trasladados a la capilla. En términos cosmológicos, la capilla es un puente comunicante con el plano celeste, y la expresión de los poderes de Dios y de Cristo en el pueblo. En ella permanecen los santos hasta que culminen las festividades. Durante este tiempo se nutrirán del poder que Dios emana y que será central en el proceso de combatir a las fuerzas nocturnas a lo largo del año. Este proceso se repetirá en la fiesta de San Antonio, patrono del poblado, y en las fiestas de los santos. Mientras tanto, en las últimas jornadas de la Misión Anual, hombres y mujeres se baten en torneos deportivos donde cada equipo representa a su pueblo en competencias futbolísticas. Junto al baile nocturno que clausura la fiesta, estas disputas son el escenario privilegiado para el cortejo amoroso.

En el año 2007 viajé a San Antonio esperando participar de los rituales de carnaval. Sin embargo, pronto noté que en el poblado hoy en día no se realizan festejos, a diferencia de otros sitios del área geográfica andina en las que este lapso cobra gran efervescencia ritual, como Coranzulí, donde gran número de migrantes retornan para intervenir en los eventos (Merlino y Rabey 1978), Potosí, donde las elites participan activamente de bailes, representando dramas "indígenas" (Abercrombie 1992) o la Quebrada de Humahuaca, cuyo carnaval despierta el interés de un creciente número de turistas (Costa y Karasik 1996), por citar algunos ejemplos.

En sus relatos los ancianos recuerdan los cantos y danzas

\footnotetext{
${ }^{18}$ El altar familiar se erige con la fundación de un nuevo hogar. Por regla general contiene la figura de bulto de un santo por el que se posea especial devoción (heredado o adquirido en una tienda de la ciudad), junto con otras estampas de papel y figuras de bulto menores. Se trata, pues, del lugar de protección de la casa, especialmente propicio para la comunicación con los seres celestes, como Dios, Cristo y los mismos santos.
}

de carnaval en tiempos pasados. Por entonces Salvador Aguaysol, un hombre que pasó gran parte de su vida como trabajador en los ingenios azucareros y regresó a San Antonio a edad avanzada, me contó que:

"S: Antes había de todo, bandoneón, había todo, música, pero música criolla iNo? Nada de música moderna. Todo era de folklore.

B: ¿Eso fue más o menos para que época?

S: La época era para el año...cincuenta y dos, cincuenta y dos... cincuenta y siete...

B: ¿Vivía mucha gente entonces acá?

S: Había menos gente, menos gente que hoy, menos gente... Había una casita donde vivíamos yo con mi mamá, otras casitas, y la municipalidad. Después... todo campo."

Aunque la efervescencia ritual parece haber sido notable a mediados del siglo XX, en la actualidad las personas prefieren transportarse hasta Santa María o Amaicha (provincia de Tucumán) y sumarse allí a ceremonias masivas. Como reminiscencia de eventos anteriores, todavía puede leerse la palabra "Carnaval", escrita con pintura en la pared externa de la casa de Telma Pacheco, una mujer reconocida por sus habilidades como tejedora. Durante aquel trabajo de campo, el pausado transcurrir de las jornadas en el pueblo sólo se sacudió una noche en que hubo baile en el club local.

El mundo vuelve a convulsionarse otra vez en Semana Santa, ante un nuevo momento incierto en el calendario ritual. Los pobladores han asociado la muerte y resurrección de Cristo con un período de duelo, oscuridad y presencia de fuerzas siniestras relacionadas con el maligno o demonio y los seres vinculados con él. Por eso, de modo similar a las actividades de caza de serpientes y lagartos señaladas por Fernández Juárez (1996) para el caso de La $\mathrm{Paz}$, en San Antonio especialmente el Jueves y Viernes Santo se organizan incursiones a los cerros con el objetivo de perseguir y eliminar a estos animales. Se cree que con la muerte de cada uno se obtienen diez indulgencias, ${ }^{19}$ puesto que en el discurso local, ambos están explícitamente asociados al maligno, y pertenecen a su esfera. Yo misma he presenciado la gran exaltación que causan estas batidas, hoy ocasionales, durante las procesiones

\footnotetext{
${ }^{19}$ Esta palabra remite a la absolución de las penas causadas por la acción de pecar.
} 
a las que asistí. Es que en la narrativa cristiana, el bien y el mal miden fuerzas. Entonces, esta lucha también es escenificada en la esfera terrenal. Luego de que la prédica evangelizadora ligara la muerte de Cristo con la traición de los judíos (o judeos, de acuerdo al tópico utilizado localmente), la mito-praxis (Sahlins 1988) actuó para que, por alguna razón, las personas los vincularan al maligno y sus seres asociados. Por ello, en estas partidas de caza, los hombres se reafirman como los aliados de Cristo en la contienda cosmológica. Estas redadas, en las que las personas vencen simbólicamente a los lagartijas/serpientes/ judeos, conforman metáforas que retoman elementos de la temática cristiana. En cierto sentido, la espacialidad bíblica se vuelve una continuación de la espacialidad local.

Durante este lapso, el equilibrio de fuerzas no se ajusta del mismo modo en cada jornada. La cercanía de la Pasión y Muerte vuelve al Jueves y Viernes Santo los días más peligrosos, donde la gente puede sufrir mayor número de accidentes, especialmente quebraduras. El viernes por la mañana Cristo bendice las hierbas silvestres que los pobladores utilizan como infusiones o medicinas para ellos y sus animales. Las fuerzas se alternan el sábado, día de la víspera de la Resurrección, cuando el poder emanado de Él comienza a recuperar su fortaleza nuevamente.

En este contexto de choque entre polos cosmológicos opuestos, es el alma de los hombres lo que también entra en juego. A diferencia de agosto, que supone una reactualización de la ligazón y de las obligaciones entre los humanos y sus seres tutelares, donde el cuerpo es amenazado, ahora el sacrificio físico, el ayuno y el perdón cobran importancia para la salvación del alma (Fernández Juárez 1996: 223). Entonces, cuando el sol sale en San Antonio, las personas marchan en procesión, conquistando el espacio social salvaje e indómito de los cerros, cargando también ellos sobre sus espaldas una pesada cruz de madera y marcando el terreno con improntas hechas de vegetales, que harán las veces de estaciones del Vía Crucis. Durante el Viernes Santo las fronteras nuevamente se tornan permeables, favoreciendo la recepción en el cielo de los mensajes vinculados a la protección familiar, las normas morales y la terapéutica.

Los enlaces cosmológicos que caracterizan las fiestas descritas hasta el momento se distinguen de los asuntos políticos que tiñen las celebraciones del santo patrono el 13 de junio. Hasta hace pocos años, los pobladores se reunían en la capilla, donde llevaban a los santos de sus altares familiares, y ocasionalmente marchaban en procesión por el pueblo. Recientemente la gente comenzó a arribar desde puntos más alejados, en un movimiento promovido por el empuje que trajo la construcción del camino que une San Antonio con el valle de Santa María. Con ellos también llegó la cúpula de la estructura política y eclesiástica, atraída tal vez por el rédito que la visibilidad de cada fiesta patronal otorga. Para buena parte de la gente proveniente de Santa María, como adelanté, los pobladores de San Antonio se encuentran asociados con un pasado precolombino arquetípico. De este modo, sus productos y su saber ritual son altamente valorados. La gente local ha aprendido a sacar provecho de esta situación. En esta fecha, recibirán los productos provenientes de la ciudad (éste es el único día del año que el pueblo se ilumina, gracias al gasoil traído de Santa María), venderán o trocarán sus bienes por otros que les resulten ventajosos, y ofrecerán su terapéutica, altamente valorada (Martínez 2013c).

A nivel local, los escenarios de interacción pública y colectiva son sumamente restringidos. Habitualmente se hallan condicionados a espacios y momentos específicos, como las fiestas de los santos y la Misión Anual (Figura 2). Además, los individuos poseen dentro de la estructura socioreligiosa una relativa autonomía. Por eso, como he señalado en otra parte (Martínez 2013b), con frecuencia las amenazas contra las normas colectivas derivan en una sanción social injuriosa. Un delicado equilibrio entre el autocontrol individual y la opinión grupal posiciona a las personas dentro del sistema social (Elias 1987: 452). En este contexto, fuerzas coercitivas estimulan la participación colectiva (Durkheim 2007: 196). Así, la mayoría de la gente entiende que todos deben asistir a las celebraciones patronales, y los que no lo hacen son objeto de fuertes críticas. En una ocasión, una persona me comentó que interviene en los festejos porque lo considera "una obligación de la sociedad, sino es como que sos el peor" (Martínez 2010: 93). La fiesta patronal es, con todo, la única celebración donde el sistema de autoridad política y las instituciones locales, como la posta sanitaria y la policía, por citar algunos ejemplos, están presentes. Ellos se suman a la jerarquía religiosa para ocupar un sitio de preeminencia. 


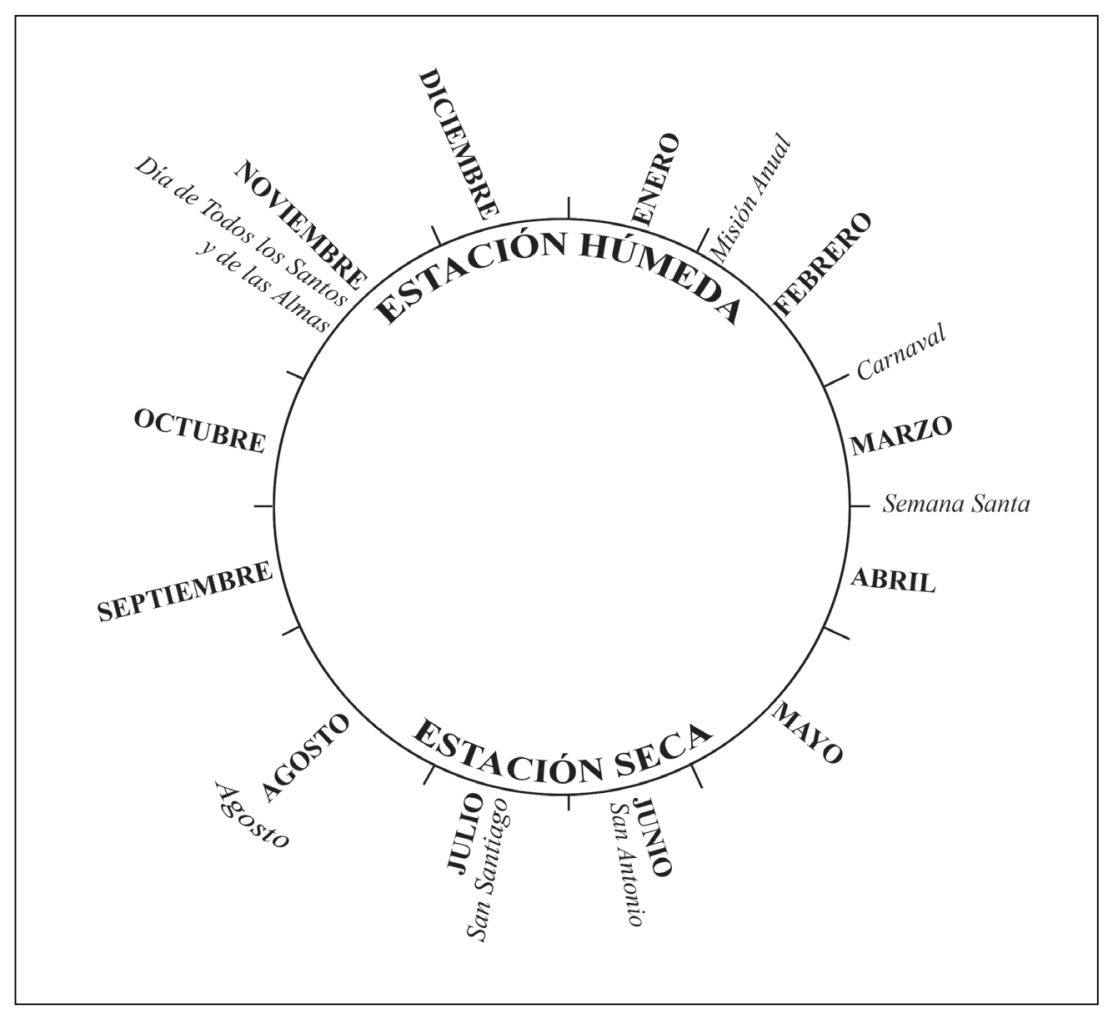

Figura 2. Ciclo ritual anual.

En el valle Calchaquí muchas celebraciones poseen carácter local, como los festejos en honor a San Santiago realizados en La Poma y Palermo (Cortázar 2008 [1949]). En San Antonio la gente celebra las fiestas de los santos de sus altares familiares, ofreciendo un banquete ritual extendido en el que invitan a participar al resto del poblado. Estos eventos se encuentran sujetos a las posibilidades de cada hogar para enfrentar su costo. Los rituales dedicados a San Cayetano, San Roque y San Santiago son los más importantes. El tercero de ellos se desarrolla el 25 de julio. Lo utilizaré como ejemplo pues casi todos son semejantes en lo referido a su estructura general.

Doña Carlota de Condorí es la dueña de la imagen de San Santiago. Ella y su esposo heredaron el santo de los padres de éste. Cuando el hombre falleció, Carlota tomó el cargo de síndico, quien en la exégesis local es la persona que debe cuidar de la figura. La acción ritual comienza cuando, días antes del 25 de julio, Santiago es trasladado en procesión a la capilla, donde se le reza una novena. ${ }^{20}$ Durante este lapso permanece allí. Finalizada la concatenación de oraciones, una nueva procesión lo devuelve a su hogar. Entonces, la anciana ofrece un banquete en una fiesta que dura toda la noche. Durante su transcurso, los hombres participan del juego de la taba, que consiste en arrojar un hueso de vaca (el astrágalo), cuya posición determinará el ganador y el perdedor de la partida. Las apuestas en dinero se destinan a la adquisición de nuevas ropas para Santiago. En el año 2008, la mujer me contó que su hijo heredaría a su muerte tanto el santo, como su rol de síndico. A su criterio, es él la persona indicada, pues junto con su esposa son los que más se han involucrado en cada una de las fiestas por ella organizadas.

Los secos, gélidos y ventosos días de junio y julio anteceden a momentos funestos. Cuando un ciclo agrícola ha finalizado y las nuevas roturaciones abren paso al

\footnotetext{
${ }^{20}$ La novena es una sucesión de rezos que transcurre durante nueve días.
} 
siguiente, llega agosto, un mes aciago. El 1, primera jornada de ese mes, está dedicado a la Pachamama. En cierto sentido, se trata de un día nefasto. Por ello, la gente dice que en esa fecha nacen las lagartijas que, como señalamos, están relacionadas con aspectos nefastos. Jocosamente, también las personas nacidas el i de agosto suelen ser llamadas lagartijos. ${ }^{21}$ Desde la perspectiva local, en este momento la tierra se encuentra convulsionada, tiembla, y en su movimiento involucra al nivel cosmológico en el que habitan los hombres. Por eso la aplacan con una larga serie de rituales que comienzan el día anterior. Así, el 31 de julio limpian sus cuerpos y amontonan la basura de sus casas, cuidando de desempolvar sus cuatro esquinas. ${ }^{22}$ Con el paso que las tinieblas dejan a la luz

${ }^{21}$ En agosto de 2009, mientras conversábamos sobre diversos aspectos, pregunté a Teresa:

"B: Me estaba comentando que los lagartijos nacen el $1^{\circ}$ de agosto ¿Qué son los lagartijos?

- T: Esos bichitos que andan por ahí en el campo, con patitas, que tienen colita. - B:Ah, sí. Pero si uno nace... Supongamos que una cabra nace el $1^{\circ}$ de agosto...

- T: Lagartija.

- B: Y, si una persona nace el $1^{\circ}$ de agosto...

- T: Lagartija.

- B: ¿También?

- T: Doña Irene, la de la esquina, nació el $1^{0}$ de agosto. Le decimos lagartija (...)."

Nuestra conversación resultó sugerente con respecto a la vinculación entre esos animales y sus asociaciones simbólicas. Si bien, como mencioné, existe una relación explícita entre las lagartijas, el maligno y lo nefasto, considero que sus significaciones no se agotan allí. Como he sugerido en otro sitio, el sistema simbólico local implica el uso de lógicas clasificatorias que expresan metáforas de los procesos que conciernen al mundo social humano. En estas formulaciones, los animales y sus atributos poseen un rol relevante (Urton 1985:254). Este animal, también llamado lagartija vallista (Liolaemusquilmes), es una especie endémica que sólo se encuentra en los Valles Calchaquíes. Un elemento que destaca en su comportamiento es su habilidad para sumergirse bajo la superficie de la tierra ante el peligro, ayudándose con sus patas traseras. Sugiero que esta habilidad para atravesar hábilmente de un estado de calma a uno amenazante, y nuevamente a la calma, constituye un atributo que la gente ha condensado simbólicamente con otro momento humano de transición similar: la convulsión de agosto. Por razones de espacio, me limitaré a estos datos, aunque dedicaré a las relaciones entre los animales y las metáforas humanas un trabajo específico.

${ }^{22}$ Estos datos son sugerentes en relación a la información que brinda Denise Arnold (1992) sobre las vinculaciones entre el cosmos y la construcción de un nuevo hogar en Qaqachaka, Bolivia. Según la autora, cuatro estacas conforman los fundamentos de la del sol, a la hora del canto del gallo (retomaré este punto), queman los desechos y las ropas viejas que descartaron, asegurándose de que se produzcan copiosas columnas de humo, vehículo que conecta el mundo donde habitan las personas, con el plano celeste (Martínez 2011). Los seres no humanos participan a la gente de lo que acontecerá mediante señales en la naturaleza. De este modo, tal como ocurre en enero, en el reverso de las rocas los campesinos pueden "leer", como mapas anticipatorios, el devenir temporal. La ecuación reverso de las rocas/cantidad de humedad/propiciación desplaza, mediante un juego de operaciones metonímicas, al conjunto superficie terrestre/ cantidad de lluvias/propiciación.

El espacio cerrado de la casa y la finca marcan el carácter privado de los rituales del 1 de agosto. Para lograr sus fines, los pobladores no necesitan desplazarse fuera de los límites de la esfera doméstica, pues la casa se asemeja a un cosmos en miniatura. Aunque no puedo explayarme en extenso sobre el tema, a riesgo de simplificar en demasía, me limitaré a señalar que la construcción de una casa requiere de un modelo de relaciones sociales fundantes, donde el conjunto esencial es la pareja hombre/mujer. Como forma ideal, está orientada hacia el naciente, de igual manera que los corrales y la capilla. Pero también la acción humana en ella se rige bajo el simbolismo de la cardinalidad, como lo explicamos para el caso de los rituales asociados al sacrificio del ganado. La casa tiene, además, un centro/pozo de ofrendas que la comunica con

edificación, que además de indicar los cuatro ángulos de la casa, se relacionan con la tierra y el linaje de los ancestros de los moradores (Arnold 1992: 51). Sabemos que en el valle de Santa María, contiguo al valle de El Cajón, cuando uno de los ocupantes muere, también se recoge la basura de las cuatro esquinas de la vivienda, lo que, creemos, podría relacionarse, junto con acciones como el lavado de las ropas nueve días después de ocurrido el deceso, de intentos de eliminar los rastros del fallecido para obstaculizar su regreso. Por otra parte, la limpieza de las esquinas de la casa, del cuerpo de los hombres, y la quema de los residuos el día previo al inicio de agosto, pone en relación el nivel de la tierra, que durante esa jornada está inestable y tiembla, con el mundo de arriba al que llegan los restos a través del humo. Este último es un vehículo privilegiado para conectar a los hombres con el plano celeste (Gil García 2010). Claro que, además, tanto la muerte de una persona como el inicio de agosto son dos períodos liminales. La ausencia de datos, sin embargo, limita las posibilidades de elaborar una hipótesis explicativa sobre la importancia de las cuatro esquinas de la casa en San Antonio. 
la Pachamama (pues, recordemos, ésta no sólo es un ser cuyo dominio son los animales salvajes y los cerros, sino que también es la tierra misma). Las columnas de humo, que actúan como canales mediadores para que las ofrendas lleguen al nivel cósmico celeste, parten de un pequeño espacio delimitado en el patio. Por último, la relación adentro/afuera es socialmente significativa pues la casa es, en última instancia, el espacio humano por excelencia. ${ }^{23}$ De este modo, el modelo de la casa como microcosmos sirve de base para la actualización, en los rituales del 1 de agosto, de los vínculos entre las personas y las entidades tutelares.

Sentados en cuclillas en el suelo de tierra, mientras lanzábamos bocanadas del humo de nuestros cigarrillos en la oquedad y le arrojábamos hojas de coca, licor de café y gaseosas formando una cruz, don Aurelio González me enseñó que "la tierra tiene que comer, porque también nos da [alimentos] a nosotros". Aquel día me instruyó en el modo de propiciar los intercambios. Tocaba a nosotros mascar coca, fumar y beber para "abrir" la comunicación entre los dominios humano y no humano.

Con anterioridad adelanté que, mientras que en Semana Santa el alma es redimida con el perdón y la purificación, ahora lo que está en juego es el cuerpo. Añadiendo en sus muñecas y pantorrillas un hilo overo ${ }^{24}$ hilado hacia la izquierda, ${ }^{25}$ las personas sortean la posibilidad de contraer malestares físicos durante este mes, y también el resto del año, aunque esto último en la exégesis local no siempre es explícito. ${ }^{26}$ Es que, en términos generales, en San Antonio la izquierda está relacionada con el tratamiento de las enfermedades y con la muerte. ${ }^{27}$ Así, mien-

\footnotetext{
${ }^{23}$ Para análisis detallados sobre la casa como producto de la acción social, ver Bourdieu (2007).

${ }^{24}$ Blanco y negro. Para la fabricación del hilo zurdo (hilado hacia la izquierda) utilizado en agosto se requiere que las hebras no contengan aditivos ni tinturas.

${ }^{25}$ Sobre el simbolismo de la lateralidad puede consultarse el trabajo de Wachtel (2001 [1990]) sobre los urus de Bolivia y los estudios clásicos de Hertz (1990 [1917]), Needham (1960) y Beidelman (1961) acerca de las sociedades africanas.

${ }^{26}$ Apoya esta idea un testimonio recogido por García y Rolandi(2000:9), en el área cercana de Antofagasta de la Sierra, donde se señala que la acción ritual de agosto destinada al hogar y el cuerpo está relacionada con "limpiar la casa y sacar toda enfermedad".

${ }^{27}$ Los cadáveres llevan ceñidos a su cintura una soga similar a la que los vivientes utilizan en agosto, hilada hacia la izquierda y
}

tras que la izquierda se vincula con la afección, la derecha se relaciona con la propiciación. ${ }^{28}$

La gente sabe que no son los únicos afectados durante el mes aciago pues el mundo también lo está, y con ellos los animales y la hacienda. ${ }^{29}$ Débiles y enfermizas, las crías nacen con pocas posibilidades de supervivencia. El alimento también disminuye. Los pastos escasos y los fríos intensos se conjugan para afectar los ciclos de vida y muerte del sistema agrícola-pastoril.

Pero junto a estos eventos, ocurridos al compás de la sucesión de estaciones, la gente entiende el paso de un día a otro como una serie de discontinuidades espaciotemporales que ponen en conexión a los hombres y a las entidades tutelares con diferentes dominios. Como referiré, los ritmos del día y la noche también dan paso a conmutaciones en los hábitos de cada uno de ellos.

\section{* Dominios en disputa}

En términos generales, la distinción analítica entre los hombres y los seres poderosos encierra una amplia serie de dominios asociados, cada uno de los cuales se vincula con espacios y tiempos cosmológicos.

En el noroeste argentino, los trabajos sobre periodicidades diarias son escasos. Si bien en la introducción he apuntado una serie de investigaciones que se ocupan del conjunto del ciclo anual, o de eventos dentro de él, son pocos los estudios que mencionan la temporalidad de la jornada diaria. Uno de ellos es la indagación sobre los tapados $^{30}$ efectuada por Odina Sturzenegger (1981) en San Andrés, provincia de Salta. Allí la autora señala que las

\footnotetext{
confeccionada en fibras blancas y negras.

${ }^{28}$ Por ejemplo, en los rituales de multiplicación del ganado, el oficiante comienza su trabajo por la derecha, y culmina hacia el naciente.

${ }^{29}$ En términos generales, el sistema de clasificación local supone una división bipartita de los animales domésticos basado en el criterio comestible/no comestible. Así, los animales pertenecen a una clase no comestible integrada por los perros, los caballos y los burros. Por su lado, la clase hacienda integra a las vacas, las cabras, las llamas y los corderos, comestibles y ligados al pastoreo.

${ }^{30}$ Tapado es un término utilizado frecuentemente en el noroeste argentino para referirse a tesoros ocultos bajo la tierra.
} 
personas encuentran estos tesoros por la noche, período que "recibe la denominación de 'mala hora' por ser la 'hora del diablo'. La duración de este lapso demoníaco abarca desde la oración hasta las tres de la madrugada, momento en que comienza la "hora de Dios'" (Sturzenegger 1981: 9), que se encuentra regida por este último. El demonio, por su parte, ejerce su dominio durante la noche, que es el lapso propicio para que éste pueda encontrarse con las personas (Sturzenegger 1981). Por su parte, la etnografía realizada Mercedes Costa y Gabriela Karasik (1996) en la Quebrada de Humahaca, Jujuy, puntualiza que la "mala hora" es el lapso donde se desentierra el carnaval. Finalmente, el estudio llevado a cabo por María Luisa Rubinelli (2000) en la misma región sugiere que la medianoche y el mediodía constituyen momentos de transición, donde "es posible la circulación entre los niveles" (2000: 152). Las horas del descanso luego del mediodía, el lapso entre las tres y cuatro de la madrugada, así como el atardecer, "encierran la posibilidad de encuentros con espíritus, diablos o condenados" (2000: 152). Aunque no ahonda en la descripción de lo que puntualiza como "niveles" o "espíritus", por citar algunos ejemplos, es posible identificar un esquema de división del tiempo diario similar al de San Antonio, en el que, como señalaré, los hitos se sitúan al mediodía, al atardecer, a la medianoche y en el amanecer.

A nivel local, con el sol del mediodía las personas tienen en sus manos el control de la vida social más que en ningún otro momento de la jornada. Por supuesto, la intervención nunca será completa porque, como mencioné, es el Dios cristiano el último ejecutor de las fuerzas que ordenan el mundo. Sin embargo, la luz solar permite actividades que los remiten a dominios obstaculizados en otros horarios: los cerros y el río al este del poblado. El pastoreo requiere la intrusión en espacios que la gente rara vez se atrevería a recorrer por la noche.

Los peligros de los sitios marcados por una muerte, especialmente si ha sido violenta, pierden un poco de su eficacia. Es que el amanecer y la hora de la oración forman barreras fuera de las cuales los muertos no pueden moverse libremente. Salvo para enviar un mensaje preciso o asustarlos, no se muestran a los hombres. Sólo una clase de ellos puede hacerse presente: son los duendes. Mediante el rezo, las fuerzas de Dios y de los santos son las aliadas de los hombres para expulsarlos fuera de su presencia.
Los poderes del maligno y de su séquito de espíritus dependientes se abren paso a partir de la hora de la oración, cuando las primeras sombras comienzan a deslizarse sobre el valle. También marca la intromisión de los muertos en el plano terrenal y, más específicamente, en las inmediaciones del poblado, que es el espacio "domesticado" de los hombres. Los cerros, por otra parte, son el dominio de la Pachamama -en sus funciones, entre otras, de guardiana de los animales-, pero también de los muertos.

El universo simbólico tiene espacios reservados para sus muertos. En el plano territorial, los cerros son el dominio de los condenados, es decir, de aquellos difuntos que han cometido faltas graves contra el orden social..31 También, en términos ontológicos, son el lugar de lo "salvaje" y de los encuentros sexuales clandestinos.

En cambio, el pueblo es el ámbito de los humanos, el lugar "domesticado", como mencioné con anterioridad. Aquí los límites se solapan. Es que las almas irrumpen de noche en el área urbana manifestándose mediante silbidos o como vagas y difusas siluetas a la distancia. Me detendré rápidamente en este punto. En la esfera cotidiana los pastores utilizan recursos sonoros para conducir al rebaño, como los silbidos o los chasquidos que producen las hondas ${ }^{32}$ al chocar con el suelo. Cuando es nocturno, el silbido se vuelve una acción diferente y socialmente significativa porque la noche es el dominio de los muertos, del maligno y sus fuerzas nefastas. Así, está prohibido a las personas silbar durante ese lapso porque el alma de un muerto podría contestar con el mismo sonido, propiciando una comunicación no permitida entre dos órdenes distintos de existencia.

Aunque el hito cronológico llamado localmente la hora de la oración se sitúa aproximadamente a las siete de la tarde, la alternancia de las estaciones conduce a jornadas de distinta duración que condicionan el momento de aparición de la oscuridad. Es que con la caída del sol se debilita la protección divina (Figura 3). Por ello las personas ahora deben permanecer a resguardo en sus casas, amparadas

\footnotetext{
${ }^{31}$ Las definiciones acerca de quién es o no un condenado se nutren de las valoraciones de los pobladores sobre la forma de vida y sobre la muerte del fallecido (Martínez 2013b).

32 Las hondas son herramientas tejidas que permiten arrojar piedras a grandes distancias. Se utilizan para encauzar a los animales durante el pastoreo.
} 


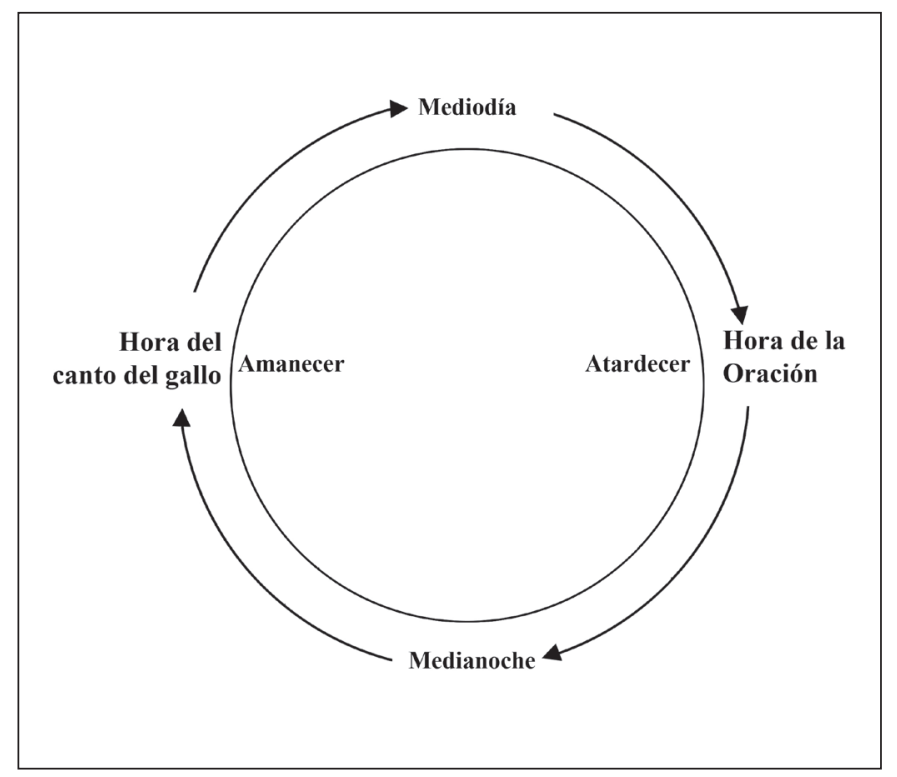

Figura 3. Esquema del ciclo diario.

por los santos de su altar familiar. Los hábitos a la vez nocturnos y diurnos de los gatos domésticos los convierten en guardianes terrenales de los hogares. Durante el día, preservan de la intromisión de animales considerados pérfidos, como las serpientes y las lagartijas que mencioné. De noche gritan y corren sobre los techos para informar a la gente sobre presencias extrañas. Para atravesar este espacio-tiempo oscuro, las personas también necesitan de sus perros negros, que son mensajeros e intermediarios vinculados con uno y otro mundo, diestros en vérselas con las fronteras que se tornan peligrosas para los hombres. Idealmente negros, durante la vida del dueño están ligados muy especialmente a su protección frente a los seres nocturnos, como el maligno y los muertos. En los rituales de muerte, tienen la función de escolta y guía en los escollos postmortem que debe sortear el recientemente fallecido (Martínez 2013b)

Como un espacio-tiempo liminal donde los seres miden sus fuerzas, la medianoche es el escenario de los rituales que enfrentan, por un lado, los poderes del maligno y sus espíritus asociados, y por el otro, las capacidades de sanación que Dios entregó a algunos hombres. Ahora, nuevamente las personas son los aliados de Cristo en la contienda cosmológica. Así, por ejemplo, en los casos severos de enfermos de susto, el alma sólo puede reinte- grarse a costa de una batalla ritual, con final incierto, a las doce de la noche.

Cuando el susto afecta a los niños, la mayor parte de los adultos puede curarlo colocando sus ropas en el lugar donde éste se produjo, llamando a viva voz al alma del pequeño. Según me contó don Luciano Aguirre, un solitario hombre que habita la casa contigua al hogar donde me hospedé numerosas veces, los casos que involucran a un adulto son más complejos, y requieren de la participación de una persona con "poder" que actúa en conjunto con dos colaboradores especialmente escogidos por él entre las personas que considera más valientes. Según me explicó, el tratamiento terapéutico aplicado a la esposa de don Alberto Pacheco, que habita en un puesto cercano, se produjo de ese modo. Durante la medianoche, una mujer con "poder", que había sido traída especialmente desde Santa María, y dos hombres cuya bravura ella evaluara, dispusieron las ropas de la enferma en el sitio donde el alma había abandonado el cuerpo. La mujer reclamó a viva voz su regreso. Los dos acompañantes habían sido entrenados para hacer caso omiso a los fuertes sonidos que escucharan, producto de la feroz lucha con las fuerzas del maligno, que pugna por llevar el alma de la enferma consigo. Fue así que pudieron recomponerla a su estado de salud anterior. 
Cuando el sol sale nuevamente, a la hora del canto del ga$l l o$, se inicia un nuevo período de transición. El sol vuelve a imponer el orden en un mundo que transitoriamente estuvo invertido: ahora los muertos, el maligno y sus socios se repliegan, cediendo el terreno nuevamente a los hombres. Con sus prácticas, ellos transforman otra vez a estos lugares en su dominio.

Sintetizando, la jornada organiza coherentemente el mundo a través del cual los seres humanos y los seres poderosos, el paisaje y el espacio-tiempo se interconectan.

Puede considerarse que el día y la noche son dos ámbitos cosmológicos distintos que condicionan las prácticas que en ellos se desarrollan. En este sentido, el día es el ámbito por excelencia de Dios y de lo humano mientras que, a la inversa, la noche lo es de los muertos y del maligno. Así, la hora de la oración/medianoche/hora del canto del gallo/mediodía, como categorías del espacio-tiempo, limitan la acción y el dominio de los muertos, el maligno y su séquito, pero también la esfera de los hombres. Aunque las fronteras son permeables, cada una de ellas se despliega sobre la otra cuando entra en actividad. Así, mientras los muertos penetran al espacio "domesticado" de los vivientes por la noche, la luz del sol permite que las personas conquisten los cerros con una actividad del orden social humano: el pastoreo. Claro que los cerros nunca dejan de ser el plano "salvaje"; por eso, como mencioné, son el escenario de la sexualidad desbordada. Con el sol del mediodía los hombres despliegan su potencial bajo la tutela de Dios y los santos. En la medianoche, se convierten en sus aliados para vencer a las fuerzas nefastas en peligrosas sesiones terapéuticas. Los umbrales puntualizados conforman el escenario para el interjuego de poderes (Figura 4).

\begin{tabular}{|c|c|c|}
\hline & Seres & Dominios \\
\hline Día & Hombres & Cerros \\
\hline & & Pueblo \\
\hline Noche & Muertos & \\
\hline & Maligno & Cerros \\
\hline & Espíritus auxiliares & Pueblo \\
\hline
\end{tabular}

Figura 4. Asociaciones simbólicas entre discontinuidades temporales, seres y sus dominios.

\section{* Batallas de poder y réplicas terrenales}

Durante el transcurso de estas páginas he delineado distinciones cosmológicas y ontológicas de los ciclos anual y diario. En este apartado las articularé de modo más específico, aportando nueva evidencia etnográfica que completa la información anteriormente descripta. Precisaré una serie de lazos entre el ciclo anual y el ciclo diario que me permiten sugerir algunas recurrencias que exponen lineamientos de orden cosmológico y ontológico.

1. Como puntualicé, en términos generales se observa la existencia de una contienda cosmológica en la que Dios, Cristo y los hombres parecen enfrentar al maligno y sus asociados. Aunque el equilibrio entre estas fuerzas repercute, en última instancia, en virtualmente todas las actividades de los hombres, pues se trata de un principio ordenador del mundo, su puesta en escena se realiza especialmente en Semana Santa. Durante este lapso, Cristo se encuentra debilitado por su muerte, y el maligno afianza su poderío. En este momento, la intervención de los hombres es crucial. Pero no se trata de un desequilibrio de fuerzas cuya restitución clausura la disputa concluyentemente hasta el siguiente ciclo anual. En el ciclo diario, ella se replica en momentos puntuales como la medianoche, pues es luego de que el sol cae cuando las fuerzas del maligno nuevamente cobran preponderancia. Así, por ejemplo, la cura del susto expresa una nueva escenificación de la inestabilidad, en la que la potencia de Cristo es respaldada por las armas que utilizan los hombres, y que provienen directamente del Él: el agua bendita y el pan, que constituye una metáfora de su cuerpo.

2. He sugerido que la capilla es, en cierto sentido, un puente comunicante con el plano celeste. En la fiesta de San Antonio, las visitas que los santos de los altares familiares realizan al patrono reiteran aquellas que alguna vez se hacían entre sí pues, como puntualicé, en un tiempo primigenio fueron como los hombres. Se dice que en estas salutaciones las fuerzas de Dios y de Cristo impregnan a los santos que, recordemos, constituyen la figura central del altar familiar, a su vez sitio de la casa que promueve la comunicación con el cielo. La reactualización de estos poderes es relevante. Cuando el sol cae y el mundo se torna frío y oscuro, los actores nocturnos se mueven entre las sombras. Los hombres y los seres que se despliegan luego de la hora de la oración pertenecen a 
órdenes ontológicos distintos. Envueltos en la luz solar y siguiendo las acciones que rigen a la humanidad actual, como la creencia en Cristo y el pastoreo, es que los primeros se desenvuelven con soltura. Los segundos, en cambio, prefieren el espacio-tiempo nocturno. Por eso, los santos vienen a poner orden allí donde la comunicación entre estas dos dimensiones no es socialmente posible. Así, como he presenciado varias veces, por la noche, ante un sonido cuya fuente se desconoce (o, más bien, se sospecha que proviene de los seres nocturnos), las figuras de bulto de los santos son retiradas al exterior de las casas, compeliéndolos a expulsar al maligno de los alrededores. En este contexto, en un lenguaje directo, la gente me ha contado que los santos pueden poner freno a estos peligros que acechan debido al poder con el que Dios los favorece en esas visitas del ciclo anual. Por ello, en cierto sentido, puede decirse que su injerencia en este momento del ciclo diario es impulsada y favorecida por su actividad durante el ciclo anual.

3. Los rituales y libaciones a los muertos suelen estar identificados con un momento puntual del calendario: inicios de noviembre, que en San Antonio coincide con los comienzos de la estación húmeda. Además de intermediarios entre Dios, los santos y los hombres, sabemos que los muertos juegan un rol central en el ciclo productivo. Más aún, los cuerpos inhumados en la tierra (a diferencia de los depositados en nichos o bóvedas) se asocian con la fertilidad de los campos y, por extensión, con la abundancia de ganado (Martínez 2011). Incluso las precipitaciones de este período constituyen una metáfora sobre su contento o descontento con los dones recibidos. En virtud de su importancia en lo referido a la producción, no debería sorprender su injerencia diaria. Virtualmente en cada sacrificio de ganado y banquete extendido se les ofrecen libaciones. Además, aunque residan en otra esfera, y que su dominio sea la noche, gozan de cierta ubicuidad. De ahí que los hombres puedan protegerse de su aparición gracias a la compañía de un perro negro, como ya indiqué, también hábil en transponer las fronteras cosmológicas. Las personas, además, no están exentas de encontrarse con ellos durante el día debido a contingencias al interior de la sociedad local (Martínez 2010). Puede decirse algo muy similar sobre la Pachamama, a quien se dedican rituales y libaciones cuando un nuevo ciclo agrícola comienza, pero también durante los momentos del ciclo diario en que se despliega como proveedora de abundancia, y como receptora de los dones con que los hombres devuelven lo obtenido de ella. En ambos casos no parecen existir limitaciones horarias para la acción ritual, pues su ejecución se encuentra sujeta al tipo de actividades que los hombres estén llevando a cabo. Se trata de entidades con relevancia en momentos puntuales del ciclo anual y también en la jornada diaria.

4. En relación al simbolismo calendárico, he señalado cómo diversos autores (Flores Ochoa 1974; Rubinelli 2000; Martínez 2001) mostraron que en distintas poblaciones del área geográfica andina el martes y el viernes son considerados días nefastos. Señalé también que en San Antonio ambas jornadas son socialmente significativas. En ellas la acción de la gente se encuentra condicionada por diversos tabúes.

Como mencioné en otro sitio (Martínez 2011), en el poblado la reinvención cultural y la reapropiación selectiva ha dado lugar a metáforas y símbolos que abrevan en el horizonte histórico y la narrativa cristiana. Desde mi punto de vista, los condicionamientos culturales que rigen sobre el martes y el viernes constituyen otro ejemplo de estos procesos. Entre otras actividades, durante mi trabajo de campo en el lugar muchas veces compartí extensas jornadas de rezos dedicados a distintos santos, novenas, misas, y otras actividades religiosas. Así aprendí que en el Rosario Cristino, ambas jornadas se encuentran dedicadas a los Misterios Dolorosos. Estos describen escenas bíblicas sobre la vida de Cristo. En el primero se lo representa orando en un huerto, mientras suda sangre. En el segundo, su cuerpo es flagelado a latigazos. El tercero menciona que es desnudado, luego vestido por una túnica roja, coronado por un ramo de espinas que lo hieren y, finalmente, burlado a gritos. El cuarto, expresa su agónico tránsito hasta el monte Gólgota, sitio donde, en la narrativa cristiana, es crucificado. El quinto relata su agonía, la despedida de su madre, y finalmente su muerte. En términos generales, los Misterios Dolorosos se reiteran siempre en cada rezo del Rosario que se realice un martes o un viernes, y remiten a los padecimientos de Cristo que en el calendario anual se rememoran en Semana Santa. Además, son los únicos Misterios que relatan escenas de su vida relacionada con aspectos perjudiciales, pues el resto menciona hitos como su nacimiento, su presentación en el templo, o su resurrección, por citar algunos ejemplos. 
Desde mi perspectiva, la gente de San Antonio ha realizado una síntesis simbólica en la que las jornadas adversas para Cristo son también nefastas para ellos, sus aliados. Durante sus lapsos es cuando más corren peligro. También, como señalé, es considerada una mala señal que el año se inicie esos días. Es que los hechos sangrientos que allí se narran parecieran expresar nuevamente el desequilibrio en la balanza de poder. Con Cristo debilitado, el martes y el viernes se tornan "del demonio", como me han mencionado numerosas veces. Por eso sahúman sus casas, expulsándolo. También evitan carnear a sus animales, ya que con ello podría "mermar la cantidad que uno tiene", según me explicaran. En la síntesis local, pareciera que los Misterios Dolorosos de la narrativa bíbli$\mathrm{ca}$, que trazan los padecimientos de Cristo, dan lugar a que las fuerzas del maligno cobren otra vez una efímera preponderancia, fatal para las personas y la procreación del mundo.

\section{* Consideraciones finales}

Como adelanté, los seres que pueblan el mundo alternan su participación en el ciclo anual, recapitulando también eventos cosmológicos en una escala acotada, durante el ciclo diario.

En términos generales, es posible describir la cosmología cajonista como una puja entre los poderes de Dios, Cristo, el maligno y sus seres auxiliares, en la que los hombres participan activamente. Cada uno de ellos posee distintivas especificidades ontológicas. Perteneciente al plano celeste, Dios es el artífice último de las fuerzas que mueven al mundo. Nocturno habitante de las noches gélidas, el maligno despliega sus jugarretas dentro del universo simbólico local. Los santos, la Pachamama, los muertos, los duendes y los hombres participan también de esta historia. La lucha entre ambas partes se trasluce, sin embargo, a lo largo del ciclo anual, y tiene su punto álgido cuando el sol se debilita y el tiempo cálido termina, es decir, cuando la luz disminuye su intensidad: en Semana Santa. Aquí el poder de Cristo pierde algo de vigor, dando lugar momentáneamente a las fuerzas de su enemigo. Ahora la participación activa de las personas es central para inclinar la balanza a su favor. Los rezos y las procesiones a los cerros, que expresan el sacrificio corporal de Cristo y la gente, cobran preponderancia. En el ciclo diario la pugna se reactualiza cuando las personas, que realizan sus posibilidades sociales (como la agricultura y el pastoreo) con la luz del sol, se entrometen en el ámbito nocturno del maligno, actuando como socios de Cristo, por ejemplo, en los procesos de curación del susto, donde ambas partes intervienen.

Los santos, modelos de la relación entre las personas, tienen sus momentos específicos en el ciclo anual. Después de residir en la capilla (morada de Dios en el pueblo) durante las fiestas patronales o de los santos familiares, sus potencias aumentan y pueden interceder en favor de los hombres el resto del año. Así, impregnados del poder de Dios, se entrometen protegiéndolos cuando las oscuras fuerzas nocturnas los acechan. También intervienen ante Dios, trasladando peticiones al plano celeste. Los muertos, como otros seres del universo local, también son ambivalentes. Es por ello que los hombres manipulan con dones sus fuerzas durante el 1 y 2 de noviembre, aunque los recuerdan alimentándolos en cada banquete ritual durante todo el ciclo anual. A la par, saben que deben protegerse de ellos, especialmente por la noche.

Además de estas caracterizaciones cosmológicas, he analizado la presencia de una amplia serie de correlaciones simbólicas. Ellas se observan, por ejemplo, en la relación entre el día y la noche. He sugerido que el día permite la realización de acciones que hacen posible la vida de los hombres, como el pastoreo. El momento en que la luz se oculta emerge un umbral, más allá del cual la noche se convierte en un nuevo lugar cosmológico. El espacio cambia sus propiedades y ahora es habitado por otros seres, como el maligno, sus asociados, y los muertos. Es entonces cuando las personas deben protegerse de este tiempo-espacio peligroso, y lo hacen, por ejemplo, a través de acción de los santos. En este contexto, como estudié para el caso del silbido, lo que define el valor de una práctica no es tanto la acción en sí misma sino la construcción simbólica que de ella se hace en base a contingencias espaciales y temporales específicas.

Las actividades de las personas también se encuentran condicionadas durante algunos días. Hemos puntualizado que los martes y los viernes son considerados nefastos, y se hallan en ocasiones relacionados con el demonio. Algunas labores, como por ejemplo las vinculadas con la matanza de ganado, están vedadas. Según 
he analizado en otro sitio (Martínez 2011), mediante procesos de creatividad cultural las personas de San Antonio han elaborado síntesis simbólicas que toman a la narrativa bíblica como materia prima. Desde mi perspectiva, las validaciones sobre ambas jornadas constituyen otros ejemplos de estos procesos. Según puntualicé, los rezos destinados a estos días muestran episodios nefastos para Cristo, que recuerdan a la Semana Santa, cuando su poder se halla debilitado. A nivel local, este nuevo desequilibrio de fuerzas entre Dios y el maligno pareciera promover nuevamente una cierta inestabilidad que pone en peligro a las personas, volviéndose un lapso adverso también para ellas.

Por otra parte, en cuanto al eje este-oeste, pareciera que en San Antonio estaría operando un principio mediante el cual donde el este se vincula con el nacimiento y la procreación, mientras que el oeste se relacionaría con el mundo de los muertos y la imposibilidad de crecimiento (por ellos los rituales relacionados con la fertilidad explícitamente no se efectúan siguiendo esa cardinalidad). A nivel local, esta correlación simbólica se aplica a una variedad de fenómenos, desde el carneo de los animales hasta la orientación de las camas en las que las personas descansan.

En estas construcciones conflictivas se encuentran el pasado, el presente y lo que vendrá, a través de los resultados del próximo año agrícola. De este modo, para mejorar la comprensión de los ciclos anuales y diarios de San Antonio, podemos concebirlos como hechos de intercambio donde se manifiestan eventos siempre atravesados por la experiencia mítica y el poder.

Agradecimientos Agradezco a la gente de El Cajón por su hospitalidad y generosidad. Estoy en deuda con Gilles Rivière y Pablo Wright por los fructíferos comentarios a este trabajo. Recibí la ayuda de Joaquín Izaguirre para la elaboración del mapa y los esquemas que acompaño. Debo una gratitud especial a los evaluadores por la atenta lectura de estas páginas. Finalmente, agradezco a las instituciones que financiaron mis estudios: el CONICET, la Universidad de Buenos Aires a través de los proyectos U.B.A.C.y T. (Foo9, F2O2, F150 y 20020100100755 ) y la Agencia Nacional de Promoción Científica y Tecnológica por medio del proyecto PICT (2011-1907).

\section{* Referencias citadas}

ABERCROMBIE, T. 2006 [1998]. Caminos de la memoria y el poder. Etnografia e historia en una comunidad andina. IFEA/IEB/ASDI, La Paz.

1992. La fiesta del carnaval postcolonial en Oruro: clase, etnicidad y nacionalismo en la danza folklórica. Revista Andina 10(2): 279-325.

AMBROSETTI, J. B. 2001 [1917]. Supersticiones y leyendas. Emecé Editores, Buenos Aires

ARNOLD, D. 1992. La casa de adobe y piedras del inka. Género, memoria y cosmos en Qaqachaka. En Hacia un orden andino de las cosas, D. Arnold, D. Jiménez y J. D. Yapita (Eds.), pp. 31-108. HISBOL/ILCA, La Paz.

AVENBURG, K. 2011. Interpellation and Performance: The Construction of Identities through Musical Experience in the Virgen del Rosario Fiesta in Iruya, Argentina. Latin American Perspectives 39: 134-149.
BEIDELMAN, T. O. 1961. Right and Left Hand among the Kaguru: A Note on Symbolic Classification. Journal of the International African Institute 31(3): 250-257.

BIANCHETTI, M. C. 1984. La creencia como mecanismo ordenador de los aspectos morales y socioculturales. Mimeo.

BLOCH, M. 1977. The past and the present in the present. Man $12(2): 278-292$.

BOURDIEU, P. 2007. Elsentido práctico. Siglo XXI Editores, Buenos Aires.

BUGALLO, L. 2010. La estética de la crianza. Los santos protectores del ganado en la Puna de Jujuy. En Arte indígena. Categorías, prácticas, objetos, M. A. Bovisio y M. Penhos (Coords.), pp. 85102. Encuentro Grupo Editor, Córdoba.

CORTAZAR, A. R. 2008 [1949]. El carnaval en el folklore calchaquí. Ediciones del Robledal, Salta. 
Dios, Cristo y el maligno: disputas cosmológicas y Ciclos temporales en San Antonio del Cajón...

COSTA, M. y KARASIK, G. 1996. ¿Supay o Diablo? El carnaval en la Quebrada de Humahuaca (Provincia de Jujuy, Argentina). En Estudios sobre el sincretismo en América Central y en los Andes, N. Ross Crumrine y B. Schmelz (Eds.), pp. 219-242. Bonner Amerikanistische Studien/Holos, Bonn.

DE HOYOS, M. 2004. La ocupación incaica en el Valle del Cajón. Anales de Arqueología y Etnología 56-58: 209-253.

DEL CAMPO TEJEDOR, A. 2006. Mal tiempo, tiempo maligno, tiempo de subversión ritual. La temposensitividad agrofestiva invernal. Revista de Dialectología y Tradiciones Populares LXI (1): $103-138$.

DESCOLA, P. 1998. Estrutura ou sentimento: a relaçao com o animal na Amazônia. Mana 4(1): 23-45.

DURKHEIM, E. 2007 [1912]. Las formas elementales de la vida religiosa. Akal, Madrid.

ELÍAS, N. 1998. La civilización de los padres y otros ensayos. Editorial Norma, Bogotá.

FERNÁNDEZ JUÁREZ, F. 2006. Kharisiris de agosto en el altiplano aymara de Bolivia. Chungara 38(1): 51-62.

2000. La tutela de las "sombras": enfermedad y cultura en el altiplano aymara. En Sustentos, aflicciones y postrimerías de los Indios en América, M. Gutiérrez Estévez (Ed.), pp. 157-191. Diálogos amerindios, Madrid.

1996. El mundo «abierto»: agosto y Semana Santa en las celebraciones rituales aymaras. Revista Española de Antropología Americana 26:205-229.

FLORES OCHOA, J. 1974. Enqa, Enqaychu illa y Khuya Rumi: aspectos mágico-religiosos entre pastores. Journal de la Société des Américanistes 63: 245-262.

GARCÍA, S. y D. ROLANDI. 2000. Relatos y ritual referidos a la Pachamama en Antofagasta de la Sierra, puna meridional argentina. Relaciones de la Sociedad Argentina de Antropología XXV: 7-25.

GAVILÁN, V. y A. M. CARRASCO. 2009. Festividades Andinas y Religiosidad en el Norte Chileno. Chungara 41(1): 101-112.

GIL GARCIA, F. 2012. Lloren las ranas, casen las aguas, conténganse los vientos. Rituales para llamar la lluvia en el centro y sur andino. Revista Española de Antropología Americana 42 (1): 145-168.

2010. De casa al cerro pasando por la iglesia. El culto al Señor de Quillacas en una comunidad de Nor Lípez (Potosí, Bolivia). Revista Española de Antropología Americana. 40(1): 261-286.
GEERTZ, C. 1997 [1973]. La interpretación de las culturas. Gedisa, Barcelona.

HERTZ, R. 1990 [1917]. La muerte. La mano derecha. Alianza editorial, México.

LAFÓN, C. R. 1970. Evangelización, calendario y conflicto cultural. Actualidad pastoral, Buenos Aires.

MARISCOTTI, A. M. 1966. Algunas supervivencias del culto a la Pachamama: el complejo ceremonial del $1^{\circ}$ de Agosto en Jujuy (NO Argentino) y sus vinculaciones. Zeitschrift für Ethnologie 91(1): 68-99.

MARTÍNEZ, B. 2014. Cartografías en tránsito: mapas orales y memoria social en El Cajón (Catamarca, Argentina). Revista Runa (en prensa).

2013a. Ritual, memoria y antepasados: el juego de los carozos en El Cajón (Catamarca, Argentina). Revista Colombiana de Antropología (en prensa).

2013b. Taxonomías de la muerte: suicidio, incesto y reciprocidad en El Cajón (Catamarca, Argentina). Nuevo Mundo, Mundos Nuevos. En línea, disponible en: http://nuevomundo.revues. org/65771; DOI: 10.4000/nuevomundo.65771 (visitado 22 de diciembre de 2013).

2013c. Imaginarios, interrelación y transformación social: El Cajón, entre la "modernidad" y el "proteccionismo". Estudios sobre las Culturas Contemporáneas Época III, Vol. XIX(38): 73-92.

2011. Ríos de agua, ríos de leche y ríos de sangre. Travesías cosmológicas del alma cajonista. Disertación doctoral, Facultad de Filosofía y Letras, Universidad de Buenos Aires, Buenos Aires.

2010. Rituales de muerte en el sector sur de los Valles Calchaquíes. En Etnografías de la muerte. Rituales, desapariciones, VIH/ SIDA y resignificación de la vida, C. Hidalgo (Comp.), pp. 87-109. CLACSO/CICCUS, Buenos Aires.

MARTÍNEZ, G. 2001. Saxra (diablo)/Pachamama; Música, tejido calendario e identidad entre los jalq'a. Estudios Atacameños 21: 133-154.

MERLINO, R. y M. RABEY, M. 1983. Pastores del altiplano andino meridional: religiosidad, territorio y equilibrio ecológico. Allpanchis XVIII(21): 149-171.

1978. El ciclo agrario-ritual en la puna argentina. Relaciones de la Sociedad Argentina de Antropología 12: 47-70. 
NATES CRUZ, B. 2009. Pensar el mundo, practicar el entorno. Etnografías y reflexiones desde una antropología de las territorialidades. Revista de Dialectología y Tradiciones Populares LXIV(1): 277-296.

NEEDHAM, R. 1960. The Left Hand of the Mugwe: An Analytical Note on the Structure of Meru Symbolism. Journal of the International African Institute 30(1):20-33.

RANDALL, R. 1982. Qoyllur Rit' I, an inca fiesta of the Pleiades: reflections on time \& space in the Andean word. Bulletin de l'Institut français d'études andines XI(1-2): 37-81.

RIVIÈRE, G. 1991. Lik'ichiriy kharisiri... A propósito de las representaciones del "otro" en la sociedad ayamara. Bulletin de l'Institut français d'études andines 20(1): 23-40.

RUBINELLI, M. L. 2000. Los ordenadores simbólicos de la concepción espacio-temporal del NOA. Cuadernos 13: 141-159.

SAHLINS, M. 1988. Islas de historia. Gedisa, Barcelona.
SPIVAK, G. 1987. In Other Worlds. Essays in Cultural Politics. Methuen, New York.

STURZENEGGER, O. 1981. En torno a los tapados. Entregas del Instituto Tilcara 12: 1-17.

URTON, G. 1985. Animal myths and metaphors in South America. University of Utah Press, Salt Lake City.

VILCA, M. 2009. Más allá del "paisaje". El espacio de la Puna y Quebrada de Jujuy: ¿comensal, anfitrión o interlocutor? Cuadernos 36: 245-259.

WACHTEL, N. 2001 [1999]. El regreso de los antepasados. Los indios urus de Bolivia, del siglo XX al XVI. Fondo de Cultura Económica, México.

ZUIDEMA, T. 1981.Inca observations of the solar and lunar passages through zenith and anti-zenith at Cuzco. En Archaeoastronomy in the Americas, R. Williamson (Ed.), pp. 319-342. Ballena Press, Los Altos, California. 